\title{
Lung age and respiratory muscle strength in female volleyball players
}

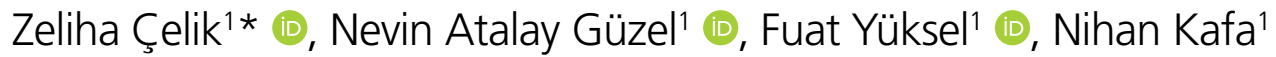

\section{SUMMARY}

OBJECTIVE: Lung age estimation is a useful approach to determine pulmonary pathologies. In literature, no studies have evaluated and compared lung age in athletes with healthy volunteers. This study aims to compare lung age and respiratory muscle strength in female volleyball players and age-matched healthy volunteers.

METHODS: A total of 18 female volleyball players (22.39 \pm 4.97 years) and 20 female healthy volunteers ( $24.85 \pm 3.33$ years) were included. Pulmonary functions and respiratory muscle strength were assessed using a spirometer and mouth pressure device, respectively. The lung age was calculated using reference equations associated with gender, height, and forced expiratory volume in 1 second.

RESULTS: Lung age was significantly lower, and forced expiratory volume in $1 \mathrm{~L}$, forced vital capacity, and maximal inspiratory and expiratory pressure $\left(\mathrm{cmH}_{2} \mathrm{O}, \%\right)$ were higher in female volleyball players compared with healthy volunteers $(p \leq 0.05)$.

CONCLUSION: The lung age and respiratory muscle strength of female volleyball players were better than healthy volunteers. Regular training in female volleyball players may improve respiratory functions and lung age.

KEYWORDS: Lung. Aging. Respiratory muscles. Athletes.

\section{INTRODUCTION}

Lung age estimation is one of the approaches to better understand pulmonary function abnormalities ${ }^{1}$. After the first lung age equation was produced by Morris et al. in $1985^{1}$, many equation varieties have been developed based on age, race, gender, and lung volumes such as forced expiratory volume in 1 second $\left(\mathrm{FEV}_{1}\right)^{2}$. Most studies have used lung age estimation for motivational smoking cessation counseling ${ }^{2,3}$. The lung age estimation was also used to estimate postoperative pulmonary complication risk in patients with lung cancer ${ }^{4}$. One study focused on patients with morbid obesity who have higher lung age compared with controls 5 .

Increased respiratory muscle strength may result in better performance. Regular evaluation of pulmonary functions and respiratory muscle strength is helpful for maintaining performance in athletes ${ }^{6}$. Respiratory symptoms such as asthma-like symptoms, exercise-induced bronchospasm, and cough are commonly reported in athletes ${ }^{7}$. Lung age is a useful method in detecting respiratory pathologies ${ }^{4}$. Furthermore, pulmonary aging is associated with internal factors such as genetic structure and mutations, systemic changes and inflammations, pulmonary structural changes, and lifestyle and external factors such as environmental exposure. Therefore, evaluation of lung age may provide important information about these factors ${ }^{8}$. In the literature, no studies have evaluated and compared lung age in athletes with healthy volunteers. This study aimed to compare lung age and respiratory muscle strength in female volleyball players and age-matched female healthy volunteers. In this study, we tested the hypothesis that female volleyball players may have later pulmonary aging and better respiratory muscle strength compared to female healthy volunteers.

${ }^{1}$ Gazi University, Faculty of Health Sciences, Department of Physiotherapy and Rehabilitation - Ankara, Turkey.

*Corresponding author: zelihacelik@gazi.edu.tr, zelihacelik1@hotmail.com

Conflicts of interest: the authors declare there are no conflicts of interest. Funding: none.

Received on July 26, 2021. Accepted on August 17, 2021. 


\section{METHODS}

This was a cross-sectional, retrospective study, in which 18 female volleyball players (22.39 \pm 4.97 years) and 20 female healthy volunteers $(24.85 \pm 3.33$ years) who do not follow a regular exercise were included from recorded data during usual care. Participants aged $<18$ years and who have a history of smoking, COVID-19, and chronic pulmonary disease were excluded. The study was approved by the Ethics Committee of the Gazi University (No. 2021-659).

Demographic characteristics, such as age, weight, height, and body mass index of participants, were regularly recorded during a routine control.

Inspiratory and expiratory muscle strength was measured using a portable mouth pressure device (Micro Medical MicroRM, UK) according to the recommendations from guidelines ${ }^{9}$. The assessments of maximal inspiratory pressure (MIP) and maximal expiratory pressure (MEP) were performed at least five times, and the highest value was selected for analysis. The percentages of inspiratory and expiratory muscle strength predicted values were calculated in accordance with reference equations ${ }^{10}$.

$\mathrm{FEV}_{1}$, forced vital capacity (FVC), and $\mathrm{FEV}_{1} / \mathrm{FVC}$ ratio were evaluated using a portable spirometer (Cosmed, Class II/Internally Powered Equipment, Italy). The highest value of the measured lung volumes at least three times was selected for analysis. The percentages of the predicted values were calculated based on reference equations ${ }^{11}$.

The lung age estimation was calculated based on a reference equation for female adults developed by Newbury et al. The formula: Lung age (years) $=1.33 \times$ Height (cm)-31.98 $\times$ ObservedFEV $_{1}-74.65$ was used to calculate the lung age of all participants ${ }^{2}$.

\section{Statistical analysis}

Statistical analyses were performed using SPSS statistical analysis program version 20.0 (SPSS Inc., Chicago, IL, USA). Descriptive variables were expressed as mean difference, $95 \%$ confidence interval $(95 \% \mathrm{CI})$, means $(\mathrm{X})$-standard deviation (SD), median-interquartile range (IQR), and percentage (\%). Shapiro-Wilk test was performed to evaluate the normal distribution of data. Student's t-test, Mann-Whitney U test, and $\chi^{2}$ test were used to compare normally distributed, non-normally distributed, and categorical variables, respectively. The level of statistical significance was described as $\mathrm{p} \leq 0.05$. In this study, we planned at least 15 participants in each group based on the results of this study using the lung age estimation values for 95\% power (G*Power 3.0.10 system, Franz Faul, Universität Kiel, Germany) $)^{12}$.

\section{RESULTS}

Notably, 18 of 52 players and 20 of 27 healthy volunteers were selected for analysis. As shown in Table 1, demographic characteristics such as age and body mass index were similar in both players and healthy volunteers $(\mathrm{p}>0.05)$. As shown in Table 2, lung age was significantly lower, and $\mathrm{FEV}_{1}(\mathrm{~L})$, FVC (L), MIP ( $\left.\mathrm{cmH}_{2} \mathrm{O}, \%\right)$, and MEP $\left(\mathrm{cmH}_{2} \mathrm{O}, \%\right)$ were higher in players compared with healthy volunteers $(\mathrm{p} \leq 0.05)$. Both MIP and MEP values were below $80 \%$ of the predicted values in 3 (16.7\%) and $14(77.8 \%)$ players and $9(45 \%)$ and $18(90 \%)$ healthy volunteers, respectively.

\section{DISCUSSION}

This is the first study to evaluate and compare lung age in volleyball players with healthy volunteers. This study shows that the lung age was much close to chronological age in players. Inspiratory and expiratory muscle strength in players was better than healthy volunteers without any chronic disease and regular exercise habits.

Lung age provides important practical information to individuals about their pulmonary functions ${ }^{13}$. Although the exact mechanism of lung aging is not known, structural changes,

Table 1. Demographic and clinical characteristics in volleyball players and healthy volunteers.

\begin{tabular}{|c|c|c|c|}
\hline & $\begin{array}{l}\text { Volleyball players } \\
(\mathrm{n}=18) \\
\mathrm{X} \pm \mathrm{SD} / \text { median (IQR) }\end{array}$ & $\begin{array}{l}\text { Healthy volunteers } \\
\qquad(\mathrm{n}=20) \\
X \pm S D / \text { median (IQR) }\end{array}$ & p-value \\
\hline Age, years & $22.39 \pm 4.97$ & $24.85 \pm 3.33$ & 0.079 \\
\hline Weight, kg & $67.80(61.45-71.68)$ & $58.50(53.25-65.00)$ & $0.009 *$ \\
\hline Height, cm & $176.50(171.75-183.75)$ & $165.00(162.75-168.75)$ & $<0.001 *$ \\
\hline Body mass index, $\mathrm{kg} / \mathrm{m}^{2}$ & $21.52 \pm 1.64$ & $22.01 \pm 2.91$ & 0.539 \\
\hline Sports age, years & $12.06 \pm 5.96$ & & \\
\hline
\end{tabular}

SD: standard deviation; IQR: interquartile range. Descriptive analyses were expressed as X \pm SD and median (IQR) for normally and non-normally distributed, respectively. *Mann-Whitney $U$ test $(p<0.05)$. Statistically significant $p$-value were written in bold. 
genetic predisposition, environmental exposure, inflammation, and chronic diseases have serious effects on pulmonary aging. A lung age greater than the chronological age indicates poorer pulmonary functions ${ }^{13}$. Many studies used it as a motivation tool for counseling of smoking cessation since smoking causes an increased lung age associated with a decrease in $\mathrm{FEV}_{1}^{1-3,14}$. In addition, some studies showed that lung age is a significant predictor in determining postoperative complications and survival $^{4,13}$. Moreover, one study found that lung age is higher in morbidly obese women compared with the control group and is positively correlated with body mass index 5 . The previously mentioned studies have developed different formulas for different ethnicities, ages, and spirometric measurements. However, there is no clear consensus on the most appropriate formula ${ }^{15,16}$. In our study, whether sport improves lung age using the formula developed by Newbury et al. ${ }^{2}$ remains the main focus. The current study found that the difference between lung age and chronological age is less in players compared with healthy volunteers. Furthermore, although all participants in groups were nonsmokers, did not have any chronic diseases, and had the same age and body mass index, the lung age of players was better than healthy volunteers. Sports enhance lung growth and pulmonary functions ${ }^{17}$. Therefore, this improvement in players may be attributable to the benefits of physical fitness and steady training.

Previous studies have emphasized better lung function in all athletes compared with nonathletes ${ }^{18,19}$. Contrary to these studies, Mazic et al. ${ }^{20}$ found that FVC values of volleyball players were lower than controls and the percentages of $\mathrm{FEV}_{1}$ values were similar in both the groups. Similar to the results of Mazic et al., the results of our study showed that the percentages of lung volumes were not statistically different in both the groups. In addition, the types of sport, age, height, and weight are associated with pulmonary functions ${ }^{11,20}$. Regular physical exercise improves cardiorespiratory fitness and decreases negative consequences of aging ${ }^{21}$. Better lung age of players may be related to the effects of regular training, and sports may delay lung aging. Other factors affecting pulmonary functions in athletes should be investigated. Respiratory events such as exercise-induced bronchoconstriction and dyspnea were the prevalent reasons for decreased performance in athletes ${ }^{7}$. In addition, lung aging is related to the loss of alveolar tissue, decreased elastic recoil of the lung, and chest wall compliance ${ }^{22}$. The use of the lung age can be an option in determining respiratory problems in athletes.

Exercise training recovers cardiorespiratory fitness and improves muscle performance ${ }^{23}$. In the current study, inspiratory and expiratory muscle weakening was common in healthy volunteers who do not regularly exercise compared with players. Regular training may improve respiratory muscle performance in players involved in our study.

Ohya et al. ${ }^{24}$ evaluated respiratory muscle strength in different sports branches and showed that the type of sports has

Table 2. Comparison of lung age, respiratory muscle strength, and pulmonary functions in volleyball players and healthy volunteers.

\begin{tabular}{|c|c|c|c|c|}
\hline & $\begin{array}{l}\text { Volleyball players } \\
\quad(n=18) \\
X \pm \text { SD/median (IQR) }\end{array}$ & $\begin{array}{l}\text { Healthy volunteers } \\
\quad(\mathrm{n}=20) \\
\mathrm{X} \pm \mathrm{SD} / \text { median (IQR) }\end{array}$ & $\begin{array}{c}\text { Means difference } \\
95 \% \mathrm{CI} / \mathrm{U}\end{array}$ & p-value \\
\hline Lung age (years) & $27.93 \pm 14.02$ & $43.01 \pm 7.23$ & $-15.08(-22.86--7.29)$ & $0.001 *$ \\
\hline \multicolumn{5}{|c|}{ Pulmonary function test $(\mathrm{L})$} \\
\hline FEV1 & $4.28(3.63-4.65)$ & $3.15(3.02-3.39)$ & 26 & $<0.001 * *$ \\
\hline FVC & $4.37(4.13-4.76)$ & $3.72(3.59-3.98)$ & 82.5 & $0.004 * *$ \\
\hline \multicolumn{5}{|c|}{ Pulmonary function test (\%) } \\
\hline FEV1 & $97.50 \pm 8.02$ & $94.81 \pm 5.97$ & $2.69(-1.93-7.31)$ & 0.245 \\
\hline FVC & $98.22 \pm 8.75$ & $97.00 \pm 7.66$ & $1.23(-4.17-6.63)$ & 0.648 \\
\hline FEV1/FVC & $98.83 \pm 6.25$ & $98.31 \pm 5.39$ & $0.52(-3.31-4.35)$ & 0.784 \\
\hline \multicolumn{5}{|c|}{ Respiratory muscle strength } \\
\hline $\operatorname{MIP}\left(\mathrm{cmH}_{2} \mathrm{O}\right)$ & $89.00 \pm 19.44$ & $74.15 \pm 23.05$ & $14.85(0.73-28.97)$ & $0.040 *$ \\
\hline MIP (\%) & $95.94 \pm 20.04$ & $81.20 \pm 25.15$ & $14.74(-0.34-29.82)$ & $0.055^{*}$ \\
\hline $\operatorname{MEP}\left(\mathrm{cmH}_{2} \mathrm{O}\right)$ & $110.11 \pm 21.30$ & $90.50 \pm 23.14$ & $19.61(4.93-34.30)$ & $0.010 *$ \\
\hline $\operatorname{MEP}(\%)$ & $69.59 \pm 13.25$ & $57.69 \pm 14.61$ & $11.90(2.69-21.12)$ & $0.013^{*}$ \\
\hline
\end{tabular}

FEV1: forced expiratory volume in $1 \mathrm{~s}$; FVC: forced vital capacity; MIP: maximal inspiratory pressure; MEP: maximal expiratory pressure; Cl: confidence

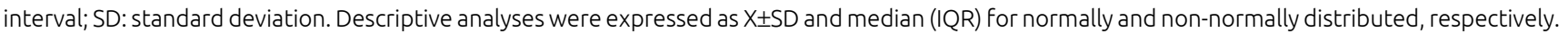
*Student's t test $(p<0.05)$. **Mann-Whitney $U$ test $(p<0.05)$. Statistically significant $p$-value were written in bold. 
an impact on MIP in female athletes. Furthermore, the aforementioned study demonstrated that inspiratory muscle strength (74.1 $\mathrm{cmH}_{2} \mathrm{O}$ ) in volleyball players is lower than other players. Inspiratory muscle strength is higher in athletes playing water sports, as previously reported ${ }^{20,24}$. In our study, inspiratory muscle strength $\left(89 \mathrm{cmH}_{2} \mathrm{O}\right)$ was higher than that expected in volleyball players and lower than swimmers, as compared with the study by Ohya et al ${ }^{24}$. Predictably, the respiratory muscles and the diaphragm of the swimmers develop more under pressure in water during breathing. Therefore, swimmers have greater lung volumes and inspiratory pressures compared with volleyball players ${ }^{20}$. The inspiratory muscle training substantially improves sports performance by reducing respiratory and limb muscle fatigue, respiratory workload, and attenuating respiratory muscle metaboreflex ${ }^{25,26}$. The effect of inspiratory muscle training on performance in different sports is still unclear. Future studies should be focused on the effect of inspiratory muscle training on performance in different sports.

The limitation of the study is that height and weight of volleyball players due to sportive characteristics were not similar to healthy volunteers.
In conclusion, lung age and respiratory muscle strength in volleyball players were better than healthy volunteers. Sports and steady training may develop these parameters in players. Further studies are needed to investigate the causes affecting lung age in athletes.

\section{ACKNOWLEDGMENT}

The authors thank Gazi University Academic Writing Research and Application Centre for their contribution and support in editing the manuscript.

\section{AUTHORS" CONTRIBUTIONS}

ZÇ: Conceptualization, Methodology, Data curation, Writing - original draft, Visualization, Investigation. NAG: Conceptualization, Methodology, Visualization, Investigation, Supervision, Writing - review \& editing. FY: Data curation, Visualization, Investigation, Supervision, Writing - review \& editing. NK: Data curation, Visualization, Investigation, Supervision, Writing - review \& editing.

\section{REFERENCES}

1. Morris JF, Temple W. Spirometric "lung age" estimation for motivating smoking cessation. Prev Med. 1985;14(5):655-62. https://doi.org/10.1016/0091-7435(85)90085-4

2. Newbury W, Newbury J, Briggs N, Crockett A. Exploring the need to update lung age equations. Prim Care Respir J 2010;19(3):242-7. https://doi.org/10.4104/pcrj.2010.00029

3. Parkes G, Greenhalgh T, Griffin M, Dent R. Effect on smoking quit rate of telling patients their lung age: the Step2quit randomised controlled trial. BMJ. 2008;336(7644):598-600. https://doi.org/10.1136/bmj.39503.582396.25

4. Haruki T, Nakamura H, Taniguchi Y, Miwa K, Adachi Y, Fujioka S. 'Lung age'predicts post-operative complications and survival in lung cancer patients. Respirology. 2010;15(3):495-500. https://doi.org/10.1111/j.1440-1843.2010.01708.x

5. Peixoto-Souza FS, Piconi-Mendes C, Baltieri L, Rasera-Junior I, Barbalho-Moulim MC, Montebelo MIL, et al. Lung age in women with morbid obesity. Rev Assoc Med Bras. 2013;59(3):265-9. https://doi.org/10.1016/j.ramb.2012.12.010

6. Jurić I, Labor S, Plavec D, Labor M. Inspiratory muscle strength affects anaerobic endurance in professional athletes. Arh Hig Rada Toksikol. 2019;70(1):42-8. https://doi.org/10.2478/aiht2019-70-3182

7. Hull JH, Ansley L, Robson-Ansley P, Parsons JP. Managing respiratory problems in athletes. Clin Med. 2012;12(4):351. https://doi.org/10.7861/clinmedicine.12-4-351

8. Brandenberger $C$, Mühlfeld $C$. Mechanisms of lung aging. Cell Tissue Res. 2017;367(3):469-80. https://doi.org/10.1007/ s00441-016-2511-x
9. Nici L, Donner C, Wouters E, Zuwallack R, Ambrosino N, Bourbeau J, et al. American thoracic society/European respiratory society statement on pulmonary rehabilitation. Am J Respir Crit Care Med. 2006;173(12):1390-413. https://doi.org/10.1164/ rccm.200508-1211ST

10. Black LF, Hyatt RE. Maximal respiratory pressures: normal values and relationship to age and sex. Am Rev Respir Dis. 1969;99(5):696-702. https://doi.org/10.1164/ arrd.1969.99.5.696

11. American Thoracic Society. Lung function testing: selection of reference values and interpretative strategies. Am Rev Respir Dis. 1991;144:1202-18. https://doi.org/10.1164/ ajrccm/144.5.1202

12. Faul F, Erdfelder E, Lang AG, Buchner A. G*Power 3: a flexible statistical power analysis program for the social, behavioral, and biomedical sciences. Behav Res Methods. 2007;39(2):17591. https://doi.org/10.3758/bf03193146

13. Ogawa F, Miyata S, Nakashima H, Matsui Y, Shiomi K, lyoda A, et al. Clinical impact of lung age on postoperative complications in non-small cell lung cancer patients aged $>70$ y. J Surg Res. 2014;188(2):373-80. https://doi.org/10.1016/j.jss.2014.01.012

14. Mitsumune $T$, Senoh E, Nishikawa H, Adachi M, Kajii E. The effect of obesity and smoking status on lung age in Japanese men. Respirology. 2009;14(5):757-60. https://doi. org/10.1111/j.1440-1843.2009.01541.x

15. Quanjer PH, Enright P. Should we use 'lung age'? Prim Care Respir J. 2010;19(3):197-9. https://doi.org/10.4104/ pcrj.2010.00045 
16. Khelifa MB, Salem HB, Sfaxi R, Chatti S, Rouatbi S, Saad HB. "Spirometric" lung age reference equations: a narrative review. Respir Physiol Neurobiol. 2018;247:31-42. https://doi. org/10.1016/j.resp.2017.08.018

17. Bovard JM, Welch JF, Houghton KM, McKenzie DC, Potts JE, Sheel AW. Does competitive swimming affect lung growth? Physiol Rep. 2018;6(15):e13816. https://doi.org/10.14814/phy2.13816

18. Doherty M, Dimitriou L. Comparison of lung volume in Greek swimmers, land based athletes, and sedentary controls using allometric scaling. Br J Sports Med. 1997;31 (4):337-41. https:// doi.org/10.1136/bjsm.31.4.337

19. Mehrotra PK, Varma N, Tiwari S, Kumar P. Pulmonary functions in Indian sportsmen playing different sports. Indian J Physiol Pharmacol. 1998;42(3):412-6. PMID: 9741658

20. Mazic S, Lazovic B, Djelic M, Suzic-Lazic J, Djordjevic-Saranovic S, Durmic T, et al. Respiratory parameters in elite athletes--does sport have an influence? Rev Port Pneumol (2006). 2015;21(4):192-7. https://doi.org/10.1016/j.rppnen.2014.12.003

21. Thyfault JP, Du M, Kraus WE, Levine JA, Booth FW. Physiology of sedentary behavior and its relationship to health outcomes. Med Sci Sports Exerc. 2015;47(6):1301. https://doi.org/10.1249/ MSS.0000000000000518
22. Verleden SE, Kirby M, Everaerts S, Vanstapel A, McDonough $\mathrm{JE}$, Verbeken EK, et al. Small airway loss in the physiologically ageing lung: a cross-sectional study in unused donor lungs. Lancet Respir Med. 2021;9(2):167-74. https://doi.org/10.1016/ S2213-2600(20)30324-6

23. Garber CE, Blissmer B, Deschenes MR, Franklin BA, Lamonte MJ, Lee I-M, et al. Quantity and quality of exercise for developing and maintaining cardiorespiratory, musculoskeletal, and neuromotor fitness in apparently healthy adults: guidance for prescribing exercise. Med Sci Sports Exerc. 2011;43(7):1334-59. https://doi.org/10.1249/ MSS.0b013e318213fefb

24. Ohya T, Hagiwara M, Chino K, Suzuki Y. Maximal inspiratory mouth pressure in Japanese elite female athletes. Respir Physiol Neurobiol. 2017;238:55-8. https://doi.org/10.1016/j. resp.2017.01.005

25. Witt JD, Guenette JA, Rupert JL, McKenzie DC, Sheel AW. Inspiratory muscle training attenuates the human respiratory muscle metaboreflex. J Physiol. 2007;584(3):1019-28. https:// doi.org/10.1113/jphysiol.2007.140855

26. Aliverti $A$. The respiratory muscles during exercise. Breathe. 2016;12(2):165-8. https://doi.org/10.1183/20734735.008116 